\title{
INTERNATIONAL TURNOVER OF QUASI-MONETARY UNITS: REGULATORY ISSUES
}

\author{
Nikita S. Voronkov \\ National Research University “Higher School of Economics”, Moscow, Russian Federation
}

Introduction: the article dwells on the international turnover of quasi-monetary units, including units of international payment systems and cryptocurrencies. Intensive digitalization of economic exchanges inextricably entails wider use of these instruments, which consequently creates the need in the development of respective regulation. Thus, the legal nature of quasi-monetary units payment system units as rights of claim to the systems operator and cryptocurrencies as specific proprietary object (a digital commodity) are being analyzed. Further in the article the law applicable to the turnover of quasi-monetary units is examined including the possibility of using lex voluntatis in settlements denominated in such units. Finally, the author considers the mandatory provisions applicable to the turnover of payment system units and cryptocurrencies.

Results: it is pointed out that considering the increasing role of quasi-monetary units in international economic turnover, conflicting approaches of national regulating authorities creates uncertainty for economic agents. It is contended that despite payment system units and cryptocurrencies serving similar economic objectives, they have fundamentally different legal nature, which creates the need for different law applicable to these types of quasimonetary units.

Conclusions: the author concludes that units of payment systems in terms of their legal nature are rights of claim to the system operator whereas cryptocurrency is a separate legal phenomenon and its nature is yet to be determined by the legal doctrine. The author has proven the paramount importance of the use of lex voluntatis by the parties to the obligation denominated in quasi-monetary units. If the parties failed to choose the law applicable, the doctrine of characteristic performance should be used. Besides, it is concluded that the national mandatory provisions can hardly be applied to quasi-monetary turnover, particularly to cryptocurrencies.

Key words: quasi-monetary units, payment system, cryptocurrency, law applicable, international turnover.

УДК 341.161

ББК 67.39

\section{МЕЖДУНАРОДНЫЙ ОБОРОТ КВАЗИДЕНЕЖНЫХ ЕДИНИЦ: ПРОБЛЕМЫ ПРАВОВОГО РЕГУЛИРОВАНИЯ}

\author{
Никита Сергеевич Воронков \\ Национальный исследовательский университет «Высшая школа экономики», \\ г. Москва, Российская Федерация
}

\footnotetext{
Введение: статья посвящена исследованию международного оборота квазиденежных единиц, в том числе расчетных единиц платежных систем и криптовалют. Информатизация экономических обменов влечет расширение сферы применения этих инструментов, что в свою очередь формирует объективную потребность в развитии соответствующего регулирования. С этой целью автором анализируется правовая природа квазиденежных единиц: расчетных единиц платежных систем как прав требования к оператору платежной системы о выплате денежных средств, криптовалюты как специфического объекта гражданских прав, представляющего собой особый цифровой товар. С помощью методов научного познания, прежде всего метода системного анализа, установлена возможность применения автономии воли сторон при осуществлении расчетов с использованием квазиденежных единиц, исследован характер и объем сверхимперативных норм, () распространяющих свое действие на оборот расчетных единиц платежных систем и криптовалюты.
} 
Результаты: отмечается, что с учетом неуклонно возрастающей роли квазиденежных единиц в международном гражданском обороте неоднозначный подход национальных регуляторов к данному институту создает для участников оборота правовую неопределенность. Указывается на то, что расчетные единицы платежных систем и криптовалюты, хотя и обладают схожим экономическим функционалом, имеют различную правовую природу, что предопределяет потребность в различном праве, применимом к данным типам квазиденежных единиц.

Выводы: автор приходит к заключению, что расчетные единицы платежных систем являются с точки зрения правовой природы правами требования клиента к оператору платежной системы, тогда как криптовалюты, обладая самобытными признаками, представляют собой особый объект гражданских прав, который доктрине лишь предстоит классифицировать. Доказана фундаментальная важность реализации сторонами расчетного обязательства с использованием квазиденежных единиц автономии воли при определении применимого права. В отсутствие такого определения следует применять доктрину характерного исполнения. Отмечены объективные сложности, связанные с применением массива национальных сверхимперативных норм к квазиденежным единицам, в особенности к криптовалютам.

Ключевые слова: квазиденежные единицы, платежная система, криптовалюта, применимое право, международный гражданский оборот.

\section{Введение}

Глобализационные процессы, происходящие в мире на протяжении последних пятидесяти лет, в корне меняют устоявшиеся представления о структуре экономических отношений. Возникают новые институты, упрощающие хозяйственное взаимодействие, развиваются системы обмена информацией, неуклонно совершенствуется деятельность финансовых организаций. Все эти факторы создают потребность в современных, более быстрых, более эффективных инструментах, опосредующих экономические процессы. Спрос на такие инструменты, безусловно, рождает предложение: использование безналичных денежных средств позволяет практически моментально осуществлять расчеты между хозяйствующими субъектами в разных государствах. Однако очевидная на сегодня тенденция к децентрализации монетарных взаимодействий, отказ от прежде неразрывной связки «государство - платежная единица» порождают и иные институты, дающие столь же широкий спектр возможностей перемещать капитал между физическими лицами и организациями как в рамках одного государства, так и из одной юрисдикции в другую.

Такими институтами являются расчетные единицы международных платежных систем, а также криптовалюты. Их появление, поистине молниеносное распространение в мире и почти повсеместное признание участниками оборота ставят перед национальными регуляторами ряд вполне естественных вопросов: какова правовая природа этих единиц? Как их регулировать? Какое право применять к ним? Применять ли к ним сверхимперативные нормы и если да, то какие и в каком объеме? Проблемы, связанные с оборотом расчетных единиц и криптовалют, конечно, далеко не исчерпываются вышеназванными. Государства как на национальном, так и на международном уровне прилагают значительные усилия, чтобы выработать унифицированные подходы к указанным институтам и создать более гомогенное регуляторное поле.

\section{Правовая природа квазиденежных единиц}

На сегодняшний день представляется возможным констатировать отсутствие единого доктринального подхода, разграничивающего криптовалюты и расчетные единицы платежных систем, несмотря на фундаментальные сущностные различия между этими инструментами [5, с. 139]. Законодательные акты большинства экономически развитых государств в связи с хронологически более ранним формированием платежных систем более обстоятельно регулируют данную сферу. Так, российское законодательство содержит понятие «электронные денежные средства», которое в Федеральном законе № 161-Ф3 «О национальной платежной системе» от 27 июня 2011 г. в ред. от 18 июля 2017 г. $^{1}$ определяется как «денежные средства, которые предварительно предоставлены одним лицом 


\section{МЕЖДУНАРОДНОЕ ПРАВО И СРАВНИТЕЛЬНОЕ ПРАВОВЕДЕНИЕ}

(лицом, предоставившим денежные средства) другому лицу, учитывающему информацию о размере предоставленных денежных средств без открытия банковского счета (обязанному лицу), для исполнения денежных обязательств лица, предоставившего денежные средства, перед третьими лицами и в отношении которых лицо, предоставившее денежные средства, имеет право передавать распоряжения исключительно с использованием электронных средств платежа» (п. 8 ст. 3).

В нормах европейского права аналогичный термин «электронные деньги» (англ. electronic money) также содержится и определяется как «хранимая электронным или магнитным способом монетарная ценность, представляющая собой право требования к эмитенту электронных денег, формирующееся при передаче денежных средств эмитенту, предназначенная для осуществления расчетов и принимаемая как средство платежа физическими и юридическими лицами, не являющимися указанным эмитентом».

С нашей точки зрения, обе нормы имеют ряд недостатков и исходят из не вполне корректного подхода к правовой природе расчетных единиц платежных систем, хотя определение, предлагаемое европейским законодателем, несомненно, является более точным. Обе дефиниции исходят из отождествления таких единиц с деньгами, что представляется ошибочным. Деньги согласно традиционной доктрине представляют собой эмитируемую государством платежную единицу, являющуюся монетарным эталоном [9, с. 580]. Связь государства (или иного публично-правового субъекта) и денег как института таким образом является неразрывной [2, с. 32]. В то же время расчетные единицы платежной системы имеют иную природу: в большинстве случаев, передавая денежные средства оператору платежной системы, клиент приобретает эмитированные таким оператором условные расчетные единицы, которые представляют собой не деньги, а право требования к платежной системе о выплате денежных средств. Так, согласно п. 5.4 Пользовательского соглашения ООО НКО «Яндекс. Деньги» зачисление электронных денег (расчетных единиц платежной системы) осуществляется после поступления денежных средств клиента на банковский счет платежной системы.

При проведении расчетов с контрагентом, также зарегистрированным в системе и имеющим виртуальный счет у данного оператора, происходит уступка права требования к системе от плательщика к получателю платежа [4]. В дальнейшем получатель платежа может распорядиться указанными единицами по своему усмотрению: конвертировать их в денежные единицы либо осуществлять дальнейшие расчеты без такой конвертации. В связи с этим представляется ошибочным постулировать тождество расчетных единиц и денежных единиц: ни платежная сила, ни действительность, ни, наконец, оборотоспособность не обеспечиваются публичным актом, а находятся в полной зависимости от исполнения платежной системой своих обязательств по заключенному с клиентом договору.

Криптовалюта, с точки зрения экономической сущности и правовой природы, представляет собой фундаментально иной монетарный механизм. В отличие от расчетных единиц платежных систем криптовалюта не имеет конкретного эмиссионного центра, осуществляющего выпуск и контроль ее обращения: напротив, эмиссия и учет носят децентрализованный характер. Платежная сила такой валюты поддерживается исключительно признанием со стороны участников оборота и экономическим механизмом спроса и предложения, а выпуск новых единиц реализуется через подключение к системе дополнительных вычислительных мощностей такими участниками. Исходя из указанной специфики возникает очевидная проблема связи криптовалюты с конкретной юрисдикцией. Ставшие уже традиционными доктринальные представления о связующих факторах, применяемых к интернет-отношениям, такие, например, как закон места нахождения сервера, со всей очевидностью не могут применяться к криптовалюте ввиду указанной децентрализации. В связи с этим для целей определения применимого права особую важность приобретает квалификация данного объекта гражданских прав с точки зрения правовой природы. В условиях отсутствия единообразного доктринального подхода к криптовалютам для поиска ответа на этот вопрос следует обратиться 
к нормативным актам и разъяснениям национальных регуляторов.

Так, Комиссия по торговле товарными фьючерсами США (англ. Commodity Futures Trading Commission), анализируя оборот биткоинов как наиболее значимой из существующих криптовалют, в Приказе от 17 сентября 2015 г. № 15-29 приходит к следующему заключению: «Биткоин представляет собой цифровое воплощение экономической ценности, которое выступает средством обмена и расчетной единицей, но не имеет статуса законного платежного средства в какой-либо юрисдикции». Регулятор, исходя из положений Закона США о товарных биржах, указывает, что биткоин подпадает под определение «товара» (англ. commodity). Однако ряд американских судов тем не менее принимали решения о привлечении к уголовной ответственности лиц, обвиняемых в отмывании биткоинов, руководствуясь законодательством о противодействии отмыванию денежных средств.

Суд ЕС в деле Skatteverket v. David Hedqvist придерживается той точки зрения, что криптовалюта является деньгами и потому конверсионные операции, осуществляемые c ее использованием, не облагаются налогом на добавленную стоимость и аналогичными сборами. Таким образом, можно констатировать очевидную несогласованность, а зачастую прямую противоречивость в позициях правоприменителей даже в рамках одной юрисдикции, не говоря о мире в целом. Вместе с тем игнорировать сложнейший и интенсивно эволюционирующий рынок криптовалют, оставляя его за рамками правового поля, было бы очевидной ошибкой.

С нашей точки зрения, криптовалюта не может считаться ни денежной единицей, ни расчетной единицей платежной системы. Деньги, как уже было сказано, характеризуются наличием эмиссионного центра и публично-правовым признанием в качестве законного платежного средства - регулируемого государством монетарного эталона. Расчетные единицы платежных систем также находятся в неразрывной связи с выпустившей их системой - в отрыве от нее их существование не представляется возможным [8, с. 18-19]. Криптовалюта указанными признаками не обладает: она не является законным платежным средством, а ее учет носит децентрализованный характер. Рассматривать ее как наличные деньги, в качестве вещи либо как безналичные денежные средства или расчетные единицы платежной системы, в качестве права требования к соответственно кредитной организации и платежной системе также невозможно [3, с. 132]. Действительность и оборотоспособность криптовалюты не обусловлены деятельностью ее создателя, а зависят от участников ее оборота и алгоритма, лежащего в ее основе.

Таким образом, наиболее точным будет ее характеристика в качестве специфического объекта гражданских прав, особого рода цифрового товара, обладающего, во-первых, нематериальной формой, во-вторых, способностью служить универсальным эквивалентом и, в-третьих, конвенциональным, то есть определяемым самими участниками оборота, механизмом определения экономического (стоимостного) содержания. Несмотря на безусловную схожесть отдельных характеристик криптовалюты с деньгами и расчетными единицами платежных систем, она обладает достаточной самобытностью для квалификации в качестве отдельного объекта гражданских прав. Однако с учетом роли и характера расчетных единиц и криптовалюты как механизмов опосредования экономических обменов и их функциональной близостью к деньгам они могут быть объединены родовым понятием «квазиденежные единицы».

\section{Применимое право и сверхимперативные нормы}

Определив правовую природу и выделив сущностные характеристики и значение квазиденежных единиц в гражданском обороте, логичным представляется обращение к вопросу о праве, применимом к расчетам с их использованием. Очевидно, что классические коллизионные формулы, относимые к деньгам и денежным обязательствам, не могут быть безоговорочно экстраполированы на квазиденежные единицы. Так, правовой режим денег в международном частном праве теснейшим образом связан с правом государства-эмитента: именно оно детерминирует их действительность, платежную силу, конвертируемость в 


\section{МЕЖДУНАРОДНОЕ ПРАВО И СРАВНИТЕЛЬНОЕ ПРАВОВЕДЕНИЕ}

другие денежные единицы и иные аспекты. Квазиденежные единицы в силу иной правовой природы порождают более сложную коллизионную проблему.

В первую очередь рассмотрим с этой точки зрения расчетные единицы платежных систем. Как уже было сказано, при осуществлении расчетов в рамках платежной системы один зарегистрированный и авторизованный пользователь осуществляет уступку прав требования к платежной системе о выплате денежных средств, внесенных ранее для пополнения виртуального счета условными расчетными единицами, другому зарегистрированному и авторизованному пользователю системы. С учетом того, что участники системы зачастую находятся в разных юрисдикциях, наиболее рациональным как для них, так и для самой системы будет использование автономии воли сторон. Такой подход используется достаточно часто: так, пользовательское соглашение платежной системы Webmoney предусматривает применение английского права к сервису денежных переводов, а аналогичные правила системы «Яндекс.Деньги» подчиняют использование сервиса праву Российской Федерации (п. 14.5 Соглашения).

Тем не менее в значительном числе платежных систем вопросы применимого права не разрешены, а автономия воли не реализована. В таком случае следует четко разграничить право, определяющее статус оператора платежной системы и правовой режим расчетных единиц, и право, применимое к самим расчетам между участниками системы. Первое следует определять исходя из места инкорпорации коммерческой организации, осуществляющей функции оператора платежной системы. Неразрывная связь расчетной единицы такой системы с деятельностью оператора обусловливает применение к ее правовому режиму того же права, что и к создавшей ее организации. В то же время расчеты между участниками системы, являющие собой уступку прав требования к системе, следует регулировать на основании права страны кредитора по такому расчетному обязательству.

Намного более сложным является коллизионное регулирование оборота криптовалют. Достаточно очевидно, что правовой статус лица, создавшего алгоритм функциониро- вания криптовалюты, никоим образом не влияет на применимое к ней право. В связи с этим вполне рациональным выглядит вопрос о том, что же является тем фактором, который связывает криптовалюту с определенной юрисдикцией. Децентрализованный учет предполагает отсутствие конкретного сервера или группы серверов, которые обрабатывают расчеты, отсутствие эмитента означает отсутствие правовой связи криптовалюты с ним. Зачастую невозможно определить и конкретную юрисдикцию, в рамках которой осуществляются расчеты [7, с. 95].

Однако в расчетах с использованием криптовалют все же присутствует элемент правоотношения, который можно связать с правом определенного государства: это субъекты расчетного обязательства. Перед включением сведений об очередной операции в блокчейн, то есть в учетную систему криптовалюты, информация, идентифицирующая стороны такой операции, становится публично доступной, что призвано обеспечить достоверность сведений в системе [1, с. 97]. В связи с этим представляется возможным применить к такого рода расчетам право страны кредитора либо право страны лица, осуществляющего решающее исполнение по обязательству, в силу которого производятся расчеты. Тем не менее использование данного коллизионного правила не является абсолютным, так как большинство криптовалют допускает существование анонимных (неперсонифицированных) аккаунтов (счетов).

На основе проведенного анализа можно констатировать, что доктрине и законодательству лишь предстоит выработать коллизионное правило, универсально применимое к обороту криптовалют. На пути создания такого правила стоят очевидные технологические ограничения, которые затрудняют достоверное установление четкой связи всех элементов расчетного правоотношения с конкретной юрисдикцией. Для преодоления этих проблем требуются значительные усилия как со стороны использующих соответствующие системы участников, так и со стороны государств. Разумеется, большинство лиц, рассчитывающихся криптовалютой, заинтересованы в стабильности таких операций и эффективной защите своих прав в случае их нарушения кон- 
трагентами. В этой связи важно, чтобы стороны самостоятельно определяли применимое к своим расчетам право, реализуя принцип автономии воли. В сущности, автономия воли на сегодняшний день является единственным эффективным механизмом определения применимого к обороту криптовалюты права, выступающего в качестве генеральной коллизионной привязки.

Квазиденежные единицы, будучи механизмом опосредования экономических обменов, несмотря на сложность определения их правовой природы, тем не менее находятся под пристальным вниманием национальных регуляторов, рассматривающих их, в особенности криптовалюту, как потенциальную угрозу финансовой стабильности и удобный инструмент для совершения правонарушений $[6$, c. 194]. Соответственно возникает проблема принципиальной применимости и объема применения сверхимперативных норм к обороту квазиденежных единиц. Речь прежде всего идет о нормах, касающихся противодействия отмыванию доходов, полученных преступным путем, и нормах о контроле за перемещением капитала.

В своем подавляющем большинстве международные платежные системы внедрили во внутренние документы своих операционных компаний нормы, обязывающие как саму систему, так и пользователей соблюдать требования законодательства о противодействии отмыванию доходов (англ. anti-money laundering - $A M L)$ и процедуры идентификации пользователей (англ. know-yourcustomer - KYC). Некоторые системы принимают дополнительные меры предосторожности: так, например, Paypal внедрила внутреннюю методологию AML и KYC-комплаенса в Европе и США. Российские платежные системы также создали «антиотмывочные» процедуры для своих сервисов: например, «Яндекс Деньги» в соответствии с Федеральным законом № 115-Ф3 «О противодействии легализации доходов, полученных преступным путем, и финансированию терроризма» от 7 августа 2001 г. в ред. от 28 декабря 2016 г. ${ }^{2}$ установила ограничения для клиентов, отказавшихся от идентификации: такие клиенты не вправе держать на виртуальном счете расчетных единиц более чем на 15 тысяч рублей и распоряжаться денежными средствами более чем на 40 тысяч рублей в месяц. Помимо требований к идентификации клиента, на расчеты в рамках платежных систем распространяются требования валютного законодательства: так, согласно п. 5.5.11 Соглашения об использовании сервиса «Яндекс. Деньги» расчеты между клиентами должны осуществляться согласно нормам законодательства о валютном контроле.

Криптовалюты являются намного более сложным объектом для применения сверхимперативных норм: в значительном числе юрисдикций, в том числе и в России, ведутся активные дискуссии о необходимости «вписать криптовалюты в правовое поле». В полном объеме обеспечить выполнение норм «антиотмывочного» законодательства при этом возможно, лишь ликвидировав анонимность расчетов, что противоречит самой сути криптовалюты. Европейский союз на сегодняшний день также придерживается достаточно осторожного подхода к криптовалюте: в Сообщении Еврокомиссии «О плане действий по усилению борьбы с финансированием терроризма» власти ЕС указывают на значительный потенциал криптовалют с точки зрения использования экстремистскими силами для своих преступных целей и необходимость регулирования. Тем не менее налицо отсутствие системных мер по распространению сверхимперативных норм по борьбе с отмыванием доходов на операции в криптовалюте в большинстве юрисдикций и недостаток понимания того, какие меры и в каком объеме необходимо применять. Исключением в данном случае выступает Япония, где в марте 2017 г. вступил в силу закон, предписывающий биткоин-биржам проводить процедуры идентификации клиента и соблюдать нормы «антиотмывочного» законодательства. Вместе с тем операции между частными пользователями попрежнему остаются в недостаточной степени урегулированными в этом отношении. Схожие проблемы наблюдаются и в реализации норм валютного законодательства.

\section{Выводы}

Таким образом, представляется возможным сформулировать ряд основных вы- 


\section{МЕЖДУНАРОДНОЕ ПРАВО И СРАВНИТЕЛЬНОЕ ПРАВОВЕДЕНИЕ}

водов на основе проведенного анализа: вопервых, расчетные единицы платежных систем и криптовалюты существенно различаются с точки зрения правовой природы: первые представляют собой права требования к оператору платежной системы о выплате денежных средств, тогда как криптовалюты являются особым объектом гражданских прав, сочетающим функции универсального эквивалента и платежного средства с одной стороны и цифрового товара с другой стороны; во-вторых, ключевой коллизионной привязкой, используемой как для расчетов через платежные системы, так и для расчетов с использованием криптовалют, является автономия воли сторон. Наряду с этим существуют объективные сложности в определении применимого к расчетам криптовалютой права в отсутствие соглашения сторон; в-третьих, сверхимперативные нормы о противодействии отмыванию доходов, полученных преступным путем, а также касающиеся валютного контроля, в полной мере применимы к расчетным единицам платежных систем и практически нереализуемы в операциях с криптовалютами.

Очевидно, что использование криптовалют и связанных с ней технологий способно революционным образом трансформировать глобальную экономику. Законодатели и правоприменительные органы должны в этой связи принимать все меры, чтобы способствовать этой трансформации, не препятствуя эволюции монетарного оборота. Вместе с тем существует объективная потребность в разумных мерах, которые не позволят недобросовестным экономическим субъектам злоупотреблять вновь открывшимися возможностями в преступных целях.

\section{ПРИМЕЧАНИЯ}

1 Собрание законодательства РФ. 2011. № 27. Ст. 3872 ; Российская газета. 2017. 21 июля (№ 160). Новая редакция настоящего закона вступила в силу с 19 июля 2017 года.

2 Собрание законодательства РФ. 2001. № 33 (ч. 1). Ст. 3418 ; 2017. № 1 (ч. 1). Ст. 46. Новая редакция настоящего закона вступила в силу с 28 июня 2017 года.

\section{СПИСОК ЛИТЕРАТУРЫ}

1. Беларев, И. А. О распределенном реестре и возможности его применения / И. А. Беларев, А. С. Обаева // Вестник Финансового университета. -2017. - № 2. - С. 94-99.

2. Кнапп, Г. Ф. Очерки государственной теории денег / Г. Ф. Кнапп. - Одесса : Тип. Э. П. Карлик, 1913. $-59 \mathrm{c}$.

3. Коростелев, М. А. Оборот электронных денежных средств: гражданско-правовые вопросы / М. А. Коростелев // Журнал российского права. 2013. - № 12. - C. 130-135.

4. Курбатов, А. Я. Правовое регулирование электронных платежных систем по законодательству Российской Федерации / А. Я. Курбатов. - Электрон. текстовые дан. - Режим доступа: http:// www.consultant.ru/cons/cgi/online.cgi? $\mathrm{req}=\mathrm{doc}$; base $=\mathrm{CJ} ; \mathrm{n}=23317 \# 0$ (дата обращения: 14.07.2017). Загл. с экрана.

5. Кутырин, В. А. Место электронных денег в системе денежных инструментов: некоторые данные к оценке рисков оборота криптовалюты и изучению проблем ее правовой регламентации / В. А. Кутырин, А. Г. Волевозд // Библиотека криминалиста. 2016. - № 3 (26). - С. 138-147.

6. Сидоренко, Э. Л. Криптовалюта как новый юридический феномен / Э. Л. Сидоренко // Общество и право. - 2016. - № 3. - С. 193-197.

7. Чурилов, А. Ю. К вопросу о правовой природе криптовалюты / А. Ю. Чурилов // Хозяйство и право. - 2016. - № 9. - С. 93-99.

8. Burau, A. Electronic money: comparative analysis of regulation in the European Union, the United States and Ukraine / A. Burau. - Central European University, 2014. - 96 p.

9. Kleiner, C. Money in private international law / C. Kleiner // Yearbook of Private International Law. 2009. - Vol. 11. - P. 565-597.

\section{REFERENCES}

1. Belarev I.A., Obaeva A.S. O raspredelennom reestre $\mathrm{i}$ vozmozhnosti ego primeneniya [On the Distributed Ledger and the Possibility of Its Use]. Vestnik Finansovogo universiteta, 2017, no. 2, pp. 94-99.

2. Knapp G.F. Ocherki gosudarstvennoy teorii deneg [Essays of the State Theory of Money]. Odessa, Tipografiya E.P. Karlik, 1913. 59 p.

3. Korostelev M.A. Oborot elektronnykh denezhnykh sredstv: grazhdansko-pravovye voprosy [Turnover of Electronic Money: Civil Law Issues]. Zhurnal rossiyskogo prava, 2013, no. 12, pp. 130-135.

4. Kurbatov A.Ya. Pravovoe regulirovanie elektronnykh platezhnykh system po zakonodatelstvu 
Н.С. Воронков. Международный оборот квазиденежных единиц: проблемы правового регулирования

Rossiyskoy Federatsii [Legal Regulation of Electronic Payment Systems under the Laws of the Russian Federation]. URL: http://www.consultant.ru/cons/cgi/ online.cgi?req $=$ doc; base $=\mathrm{CJI} ; \mathrm{n} 3317 \# 0=$.

5. Kutyrin V.A. Mesto elektronnykh deneg v sisteme denezhnykh instrumentov: nekotorye dannye k otsenke denezhnykh riskov oborota kriptovaluty i izucheniyu problem ee pravovoy reglamentatsii [Role of Electronic Money in the System of Monetary Instruments: Some Data to Assess the Risks of Crypto Currency Turnover and to the Study of the Problems of its Legal Regulation]. Biblioteka kriminalista, 2016, no. 3 (26), pp. 138-147.
6. Sidorenko E.L. Kriptovaluta kak novyy yuridicheskiy fenomen [Crypto Currency as a New Legal Phenomenon]. Obshchestvo i pravo, 2016, no. 3, pp. 193-197.

7. Churilov A. Yu. K voprosu o pravovoy prirode kriptovaluty [On the Legal Nature of Crypto Currency]. Khozyaystvo i pravo, 2016, no. 9, pp. 93-99.

8. Burau A. Electronic Money: Comparative Analysis of Regulation in the European Union, the United States and Ukraine. Central European University, 2014.96 p.

9. Kleiner C. Money in Private International Law. Yearbook of Private International Law, 2009, vol. 11, pp. 565-597.

\section{Information about the Author}

Nikita S. Voronkov, Postgraduate Student, Department of Public and Private International Law, National Research University "Higher School of Economics", Myasnitskaya St., 20, 101000 Moscow, Russian Federation, nvoronkov@hse.ru.

\section{Информация об авторе}

Никита Сергеевич Воронков, аспирант кафедры международного публичного и частного права, Национальный исследовательский университет «Высшая школа экономики», ул. Мясницкая, 20, 101000 г. Москва, Российская Федерация, nvoronkov@hse.ru. 